\title{
Breast Carcinoma Metastatic in the Central Nervous System
}

National Cancer Institute

\section{Source}

National Cancer Institute. Breast Carcinoma Metastatic in the Central Nervous System. NCl Thesaurus. Code C133501.

A carcinoma that has spread to the central nervous system from its original site in the breast, through the hematogenous route. 